\title{
O BAIRRO, UM PROJETO DE CRÍTICA EXPANDIDA
}

The NeIGHBORHOOD, A PROJECT OF EXPANDED CRITIQUE

\author{
Júlia Vasconcelos Studart
}

Nelic/ Universidade Federal de Santa Catarina

Rio de Janeiro, RJ, Brasil

PALAVRAS-CHAVE: Crítica; modernidade; fragmento; ensaio.
KEYWORDS: Criticism; modernity; fragment; essay.

PALABRAS-LLAVE: Crítica; modernidad; fragmento; ensayo.

\section{Resumo}

Este texto tem como proposição investigar a literatura do escritor angolano-português Gonçalo M. Tavares, mais especificamente a série intitulada $O$ bairro, que é uma composição para 39 livros (10 publicados até agora). O projeto elabora uma leitura crítica disseminada, ou expandida, de alguns escritores fundamentais da modernidade como nomes plenos de história que são colocados num mesmo espaço contíguo de uma esfera - O bairro. Um exercício de repetição e do uso recorrente do fragmento como recurso crítico de elaboração do pensamento numa prosa que pode ser lida entre a fabulação e o ensaio, o poema e a filosofia.

\section{Abstract}

This text seeks to investigate Gonçalo M. Tavares' fiction, more specifically the series called ' $O$ bairro' (The Neighborhood), composed of 39 books, ten of which have been published so far. The project proposes a disseminated, or expanded, critical reading of some fundamental modern writers. They are fully regarded as names inscribed in history, placed in the same contiguous space of a sphere - The Neighborhood. Tavares' writing stands out as an exercise of repetition and use of the fragment as a critical device for developing thought by means of a prose situated between fabulation and essay, poem and philosophy.

\section{Resumen}

Este texto se propone a investigar la ficción de Gonçalo M. Tavares, más específicamente la serie intitulada $O$ bairro (El barrio), que se constituye de 39 libros, 10 de los cuales ya están publicados. El proyecto elabora una lectura crítica diseminada, o expandida, de algunos de los escritores fundamentales para la modernidad como nombres inscritos en la historia que se reúnen en una misma esfera, en un espacio contiguo: el barrio. Un ejercicio de repetición y del uso recurrente del fragmento como recurso crítico de elaboración del pensamiento en una prosa que puede ser leída entre la fabulación y el ensayo, entre la poesía y la filosofía. 
A série O bairro, do escritor angolano-português Gonçalo M. Tavares, começa com a publicação do livro O Senhor Valéry, em 2002, que era apenas um livro isolado, mas depois foram publicados O Senhor Henri (2003), O Senhor Brecht (2004), O Senhor Juarroz (2004), O Senhor Kraus (2005), O Senhor Calvino (2005), O Senhor Walser (2006), O Senhor Breton (2008), O Senhor Swedenborg (2009) e O Senhor Eliot (2010). E aí se começa a ter um desenho da cartografia inoperante do bairro, um projeto em formação e futuro, em que estão previstos 39 moradores, seguindo uma estrutura que contém as "formas-trabalho da história", as "formas-duplas" de composição de uma biblioteca de interesses e de algo da história arquivante da literatura. Este projeto, em direção a uma utopia, se emenda antes como possibilidade de convivência ou estrutura relacional, como um princípio de vizinhança no seu desenho mais simples, o de uma cartografia poético-urbana, como a que Will Eisner desenha em uma de suas novelas gráficas, A Vizinhança - Avenida Dropsie. Eisner anuncia algumas ideias sobre isso no prefácio que escreve para essa novela: "Vizinhança tem períodos de vida. Elas nascem, evoluem, amadurecem e morrem" e "As pessoas, não os prédios, são o coração da matéria".* Tanto é que o próprio Gonçalo M. Tavares afirma em uma entrevista* que brinca muito com o periodismo desse bairro e que procura assemelhá-lo à lógica da aldeia de Asterix (aldeia que traz também um princípio de vizinhança), personagem de histórias em quadrinhos criadas por Albert Uderzo e René Goscinny no ano de 1959, na França. A aldeia de Asterix, assim como o bairro de Gonçalo, seria então o lugar que resiste à invasão dos bárbaros, palavra espacial que toca uma ideia de vizinhança, espaço de pequenas dimensões que parece ser a ilusão do lugar acolhedor e seguro por excelência. O desenho do bairro, que acompanha as contracapas ou as folhas de rosto das edições publicadas até agora, é extremamente norteador dessa comunidade que in-opera não como dispositivo, mas como ato e alteração:

* (EISNER, Will. A Vizinhança - Avenida Dropsie. Trad. Leandro Luigi del Manto. São Paulo: Devir, 2004: 01.)

* (TAVARES, Gonçalo M. "Quanto pesa uma palavra?". In: Cronópios, literatura e arte em meio digital. Entrevista concedida a Sissa Frota. 29 de novembro de 2009. Disponível em: <http://www.cronopios.com. br/site/artigos.asp?id=4311 > Acesso em: Nov, 2009.) 


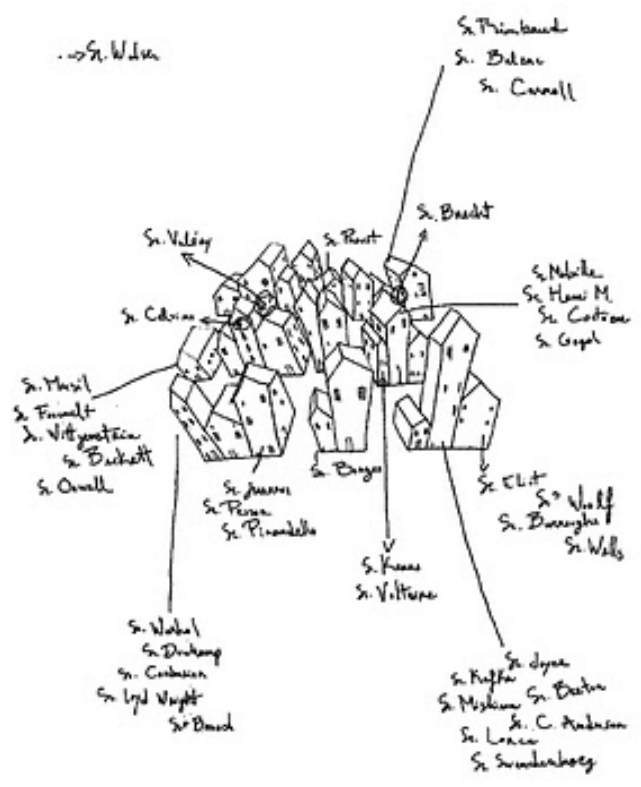

A série $O$ bairro tem relações espaciais próprias, porém modeladamente urbanas e, por isso mesmo, modernas, e que vêm de um livro anterior intitulado Biblioteca (que foi publicado junto com o primeiro livro da série, $O$ Senhor Valéry). Há nesse livro um empenho em direção ao corpo humano seguindo mais ou menos aquilo a que Benjamin expressa no seu "O narrador" como um artifício da modernidade inserido numa paisagem que mudava a cada instante e que em nada continuava como antes porque as ações da experiência estavam em baixa: o que se coloca "além das nuvens, e debaixo

* (BENJAMIN, Walter. Magia e Técnica, Arte e Politica (Obras Escolhidas; v. 1). Sérgio Paulo Rouanet (trad.). São Paulo: Brasiliense, 1985: 198) delas, num campo magnético de correntes devastadoras e explosões, o pequenino e quebradiço corpo humano".* Nesse Biblioteca, há primeiro um conhecimento por montagem entre a organização alfabética de verbetes e, depois, como conceito, a organização de uma série de textos a partir dos nomes e do trabalho dos escolhidos para compor o livro.

A ideia, quando deriva n' $O$ bairro de outra forma, passa a ser de certa maneira - trazer de volta uma constelação pormenorizada de escritores, artistas e pensadores que pudessem ser colocados num mesmo espaço contíguo de uma esfera - uma bolha - agora como moradores e, principalmente, se como moradores, numa outra 
experiência do corpo, também como artífices e como figurações do ser-em e do ser-com, ou seja, do ser-em-esferas. Faço uso do conceito de esfera proposto por Sloterdijk: para ele a esfera (que são agrupamentos, associações, bibliotecas, igrejas, partidos, estados, reinos, nações que se organizam numa conformação tanto individual como histórico-coletiva) é a redondeza aberta e repartida, onde habitam seres humanos na medida em que conseguem converter-se no que esta expressão converge. Para ele, habitar já é formar esferas e são exatamente os seres humanos os que conseguem construir mundos redondos com possibilidades abertas de horizonte. A catástrofe (que as coisas continuem exatamente como estão, segundo Benjamin), por outro lado, se dá quando essas esferas estalam provocando algo como desmoronamentos: "Lo que se llamó expulsión del Paraiso es un título mitico para la catástrofe esferológica primitiva", a isto se pode chamar também a "privación del primer complementador".* A bolha, como tal, seria "el espacio en el cual o ante el cual los hombres son primaria, propria e realmente hombres".*

O modo de operação de Gonçalo $\mathrm{M}$. Tavares na construção d'O bairro como uma esfera tem pertinência porque insiste num exercício de repetição e, depois, porque faz uso recorrente do fragmento - como recurso crítico de elaboração do pensamento numa prosa que pode ser lida entre a fabulação e o ensaio, o poema e a filosofia - para imprimir sobre o corpo-escrito dos homens (moradores de um bairro) uma teoria do espaço íntimo e, ao mesmo tempo, pensá-los como componentes de uma intensidade secreta relacional. Para Sloterdijk, a grande recusa da modernidade é a recusa do espaço íntimo. Daí a evocação feita por Gonçalo M. Tavares da imagem da bolha que vem a partir do uso do fragmento para o desenho desse bairro como um aviso da dilaceração da experiência avizinhada e, ao mesmo tempo, da manutenção de zonas íntimas e de estratos de amizade.

Mario Perniola, por sua vez, afirma que o fragmento não é senão a forma de expressão mais coerente com a modernidade por causa de sua manifesta capacidade de descontinuidade, de incoerência e de dilaceração da experiência. Para ele, aquele que pratica o fragmento é muito mais do que um escritor, é também um observador e está muito mais próximo daquele que lê o mundo, um "leitor-crítico". Este leitor-crítico se avizinharia de uma tradição e de um apontamento para o presente no gesto que se move em direção à incompletude, a uma "perfeição essencial que elimina o
* (SLOTERDIJK, Peter. Esferas I. (Microsferología) Burbujas. Isidoro Reguera (trad.). Madrid: Ediciones Siruela, 2009: 55.)

*(SLOTERDIJK, Peter; HEINRICHS, Hans-Jürgen. El soly la muerte. Madrid: Ediciones Siruela, 2004: 143.) 
* (PERNIOLA, Mario. Desgostos - novas tendências estéticas. Davi Pessoa (trad.). Florianópolis, EdUSFC, 2010: 140.)

* (Ibidem: 142.)

* (Ibidem: 150.)

* (NIETZSCHE, Wilhelm Friedrich. A gaia ciência. Tradução, notas e posfácio Paulo César de Souza. São Paulo: Companhia das Letras, 2001: 181.) modo finito".* O bairro de Gonçalo M. Tavares pode ser lido exatamente aí, nessa clave daquele que pratica o fragmento. Para Perniola, a imagem do fragmento como um "porco espinho", sugerida por Friedrich Schlegel, caracterizaria a individuação, uma dimensão integral de uma individualidade:

A celebração do fragmento segue no primeiro Romantismo alemão com a apologia da forma orgânica, contraposta à forma mecânica. Enquanto esta última é imposta de fora, a primeira se desenvolve espontaneamente a partir do interior: todavia, justamente por isso, a forma orgânica introduz uma descontinuidade no mundo, que era desconhecida pelos grandes sistemas filosóficos modernos de Descartes ou de Spinoza, e também pelo saber clássico. O fragmento é uma unidade intrínseca auto-suficiente, não a parte de uma agregação mais ampla, porque ele é antes de tudo princípio vital que se contrapõe à pedra, ao pedaço imóvel, inerte e inorgânico. O fragmento é rico, múltiplo, pleno: o primeiro Romantismo rompe, assim, a unidade do mundo sobre o qual se fundava ainda a história natural dos séculos XVII e XVIII e introduz na cultura a dimensão vital que muita importância terá na primeira metade do século XX.*

O que de fato se lê no começo do projeto de Gonçalo M. Tavares é uma tentativa de provocar um deslocamento e uma deformação naquilo que ainda podemos chamar de "cena de leitura" ou de "leitura crítica” como uma forma orgânica a partir do fragmento e no que se conhece conceitualmente como bairro. Todo o projeto parte disso e de uma ideia em torno da posse de alguns autores e de algumas formas de escrita também como formas de vida. Ou seja, a cada livro procura armar duplas, duos, enxertos, zonas de contato, como uma crítica expandida, disseminada e periódica da modernidade: "O destino da obra está em como esta se relaciona com o devir histórico da cultura; o destino da dupla depende de como esta se expande no mundo", comenta Perniola.*

O primeiro vetor dessa construção é Paul Valéry e suas, digamos, em tom de paráfrase, ideias fixas. O livro O Senhor Valéry, que seria apenas um trabalho isolado, dá início a todo o projeto d'O bairro enquanto engendra aquilo que Nietzsche propõe - "De que vale um livro que não nos transporte além dos livros?”* - e, ao mesmo tempo, estabelece o que o projeto toma como princípio: mandar para longe toda e qualquer seriedade pesada de uma tradição já incorporada por cada um desses senhores que, a partir de agora, passam a morar nesse bairro. Valéry, escolhido talvez quase aleatoriamente como primeiro morador, disse em sua "Primeira 
aula de poética" que numa obra em formação "o homem dificilmente está sozinho"* e que "Parece haver nessa ordem das coisas mentais algumas relações muito misteriosas entre o desejo e acontecimento".* O fato é que se para Valéry o tempo inteiro "apelamos aos outros", * talvez a postulação desse apelo se dê porque também o que se assinala como importância é o que reveste o corpo como zona ou superfície de contato com o mundo, "o mais profundo é a pele", ${ }^{*}$ e o que se teria a partir daí formando assim, no homem, um grande sistema sensorial para seu corpo através de seu único dado possível de entendimento, mesmo que provisório, a linguagem. Para ele, ao consultarmos nossa própria experiência, nos damos conta de que "só compreendemos os outros, e que só compreendemos a nós mesmos, graças à velocidade de nossa passagem pelas palavras".* Daí a necessidade do que ele chama de repensar, e que tal ato se cumpre para aprofundar o que ainda parece merecer ser aprofundado.

Este repensar parece muito próximo daquilo que Nietzsche elabora em seu $A$ gaia ciência, quando comenta que é uma lenta e prolongada dor que obriga o filósofo a alcançar a profundidade extrema do humano e a desvencilhar-nos de toda confiança e de toda benevolência, daquilo "tudo o que encobre, que é brando, mediano, tudo em que antes púnhamos talvez nossa humanidade. Duvido que uma tal dor 'aperfeiçoe' -; mas sei que nos aprofunda".* Por isso que para ele, dizia isso dos gregos, se faz "necessário permanecer valentemente na superfície, na dobra, na pele, adorar a aparência, acreditar em formas, em tons, em palavras, em todo o Olimpo da aparência!"* Isto é o que faz afirmar que os "gregos eram superficiais - por profundidade!"* Tudo isso também muito próximo daquilo que Sloterdijk afirma: que toda penetração profunda no mundo íntimo pressupõe a transformação de corpos sólidos em fluidos misturados a ser incorporados.*

Assim, ao tomar a dimensão do espanto com o outro - "espanto-me com a minha própria vida” -, Valéry propõe que esta é a condição do homem para poder viver uma quantidade de outras vidas além da sua, o que indica que ele pode também viver a sua própria. Por isso que, para ele, a poesia é uma arte da linguagem como uma criação da prática, que qualquer comunicação entre os homens só possui firmeza e possibilidade de verificação na prática: "Eu peço fogo a vocês. Vocês me dão fogo: vocês me compreenderam”.* Tanto que num dos textos que compõem o livro O Senhor Valéry, inti-

* (VALÉRY, Paul. Variedades. Trad. Maiza Martins de Siqueira. São Paulo: Iluminuras, 2007: 183.)

* (Idem.)

* (Ibidem: 188.)

* (Ibidem: 215)

* (Ibidem: 195.)

* (NIETZSCHE, Wilhelm Friedrich. A gaia ciência, op. cit.: 13.)

* (Ibidem: 15.)

* (Idem.)

* (SLOTERDIJK, Peter. Esferas I. (Microsferología) Burbujas. Isidoro Reguera (trad.). Madrid: Ediciones Siruela, 2009: 114.)

* (VALÉRY, Paul. Variedades., op. cit.: 200.) 
tulado "O problema dos negócios", num impasse entre comprar e vender, mas principalmente numa alternância entre partes possíveis de uma formação das circunstâncias cotidianas, tomadas como "sobrevivências", e o medo da morte que pode interromper estas mesmas circunstâncias, há uma sequência de desenhos (como se tivessem sido feitos pelo personagem Valéry de Gonçalo M. Tavares, logo estamos diante de uma incorporação ou de um pêndulo entre posse e despossessão) que traçam o percurso da circunferência como uma geometria da vida moderna e, ao mesmo tempo, como uma presença da esfera enquanto uma "parte alimenta a outra" e a existência é percebida como aquilo que pertence essencialmente a uma espacialidade que se verifica na prática:

O senhor Valéry tinha como profissão, em dias alternados, vender e comprar.

- Vendo o que comprei no dia anterior - explicava o senhor Valéry - e no dia seguinte compro algo com o dinheiro que fiz da venda do dia anterior. E assim se vai sobrevivendo - concluía.

E o senhor Valéry explicava:

- Existe a parte de cima e a parte de baixo e uma alimenta a outra.

E como gostava muito de desenhar, o senhor Valéry desenhava

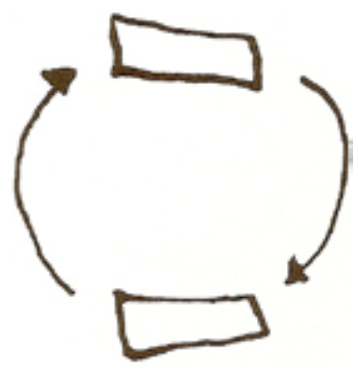

- E é porque uma parte alimenta a outra que a circunferência rola - acrescentou ainda o senhor Valéry enquanto fazia um segundo desenho 


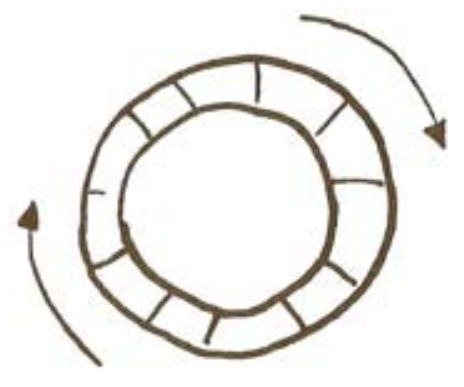

E o senhor Valéry fez ainda um terceiro desenho

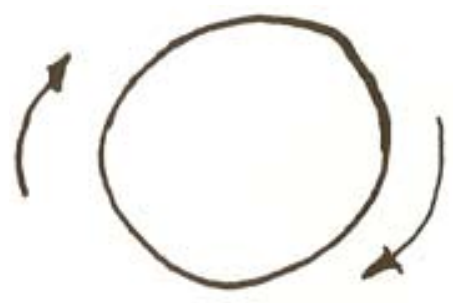

- Enquanto um dia se seguir ao outro, tudo bem. O problema deste negócio - sussurrava o senhor Valéry, como que a querer que ninguém o escutasse - o problema é se eu morro. Esse é o problema. *

O bairro pode ser figurado nesses primeiros esboços do senhor Valéry numa espécie de geometria alucinada, de máquina de efeito incerto - a linguagem e a vida, formas sensíveis e tomadas de desejo -, seguindo as setas que primeiro traçam o compasso do movimento das partes e que depois traçam o movimento de voltas incessantes num mesmo sentido em torno da circunferência para também movê-la quando até a ciência das partes, como uma separação, desaparece. As relações são sempre montadas a partir de uma modulação, que tanto pode ser entre o artifício e a natureza, por exemplo, no que trata do uso da linha reta (que vem da racionalidade, da técnica, da ciência) e da linha caótica, imprevisível, que vem da natureza. $\mathrm{O}$ que se percebe é que Gonçalo M. Tavares opta por escrever numa série de ressonâncias e empréstimos a partir de Valéry, ou seja, com Valéry e com uma voz pública que vem do pensamento e da literatura de Valéry, para o seu próprio projeto de escrita. Uma tentativa de elaboração constitutiva de conceitos a partir do fragmento que comparece entre o uso do aforismo, da ficha de anotação, de
* (TAVARES, Gonçalo M. O Senhor Valéry. Lisboa: Caminho, 2002: 41-43.) 
* (NIETZSCHE, Wilhelm Friedrich. A gaia ciência. Tradução, notas e posfácio Paulo César de Souza. São Paulo: Companhia das Letras, 2001: 285-286.)

* (NIETZSCHE, Wilhelm Friedrich. Ecce homo: como alguém se torna o que é. Trad. Paulo César de Souza. São Paulo: Companhia das Letras, 2008: 94.) raciocínios argumentativos, de ideias superpostas, da ausência de resto etc., em direção ao seu próprio modo de escrita.

Assim surge aquilo que pode ser lido como outra digestão, a partir de Nietzsche, quando é notória também no projeto a decisão de elaborar esses personagens que vêm dos escritores, pensadores e artistas não apenas como duplos, mas também como sincros de um tempo agora para a literatura e para a arte, para a instabilidade do que são, como nomes plenos de uma história e de certos dados da cultura a que fazem parte (da língua à nação, das abreviações de uma história individual e de uma história da literatura e da arte à composição de seus planos de linguagem, trabalhos e livros numa luta com as imagens), mas principalmente montar personagens que podem ser tomados e lidos como uma série de "impossíveis" dentro de um espaço esférico enquanto tenta se colocar e colocar cada um desses moradores também como bons dançarinos (tal qual o que Nietzsche propõe como o que pode ser o espirito de um filósofo), ou seja, que estejam e continuem mal colocados:

Talvez todos nós, filósofos, estejamos atualmente mal colocados em relação ao saber: a ciência cresce, os mais eruditos entre nós estão quase a descobrir que sabem muito pouco. Mas seria ainda pior se fosse diferente - se soubéssemos demais; nossa tarefa é e continua sendo, antes de tudo, não nos confundirmos com outros. Nós somos algo diferente de eruditos: embora seja inevitável que, entre outras coisas, também sejamos eruditos. Temos outras necessidades, outro crescimento, outra digestão: precisamos de mais, também precisamos de menos. Não existe fórmula para o quanto um espírito necessita para a sua nutrição; mas, se tem o gosto orientado para a independência, para o rápido ir e vir, para andanças, talvez para aventuras, de que somente os mais velozes são capazes, então prefere viver livre e com pouco alimento, do que preso e empanturrado. Não é gordura, mas maior flexibilidade e força, aquilo que um bom dançarino requer da alimentação - e eu não saberia o que um espírito de um filósofo mais poderia desejar ser, senão um bom dançarino. Pois a dança é o seu ideal, também a sua arte, e afinal sua única devoção também, seu "culto divino".*

Não me parece haver muitas dúvidas de que a elaboração do projeto de escrita de Gonçalo M. Tavares vem principalmente das leituras que fez ou faz de Nietzsche. É possível notar com veemência que um começo pode ser identificado de fato no livro de Nietzsche, Crepúsculo dos Ídolos, publicado em 1888 - como descreve o próprio Nietzsche em outro livro seu, Ecce Homo, aquele seria um livro "fatal e alegre no tom, um demônio que ri"* -, livro que tem 
como tarefa a manutenção da jovialidade e de todo um excesso de força, que recupera, de certa forma, numa ambivalência e numa articulação do neutro tão presentes em todo o seu pensamento: por exemplo entre a jovialidade e a decadência, o riso e a seriedade, a saúde e a doença, a gravidade e a leveza. Diz ele: "Manter a jovialidade [...] uma tarefa assim, um tal destino, compele a sair ao sol a todo instante e sacudir de si uma seriedade pesada, que se tornou pesada em demasia. Todo meio é bom para isso, todo 'caso' um acaso feliz. Sobretudo a guerra".* O livro se apresenta então como uma máquina de guerra, uma declaração de guerra contra os velhos ídolos, ou seja, as velhas verdades, para abrir novos caminhos na história, rejuvenescer, o que corresponde à tarefa da tresvaloração, ou ainda à tarefa do destruidor (cumprir o caráter destrutivo) proposto por Benjamin. Nietzsche ainda diz, acerca desse livro, que:

Também este livro - seu titulo já o revela - é sobretudo um descanso, um torrão banhado de sol, uma escapada para o ócio de um psicólogo. Talvez também uma nova guerra? E serão perscrutados novos ídolos?... Este pequeno livro é uma grande declaração de guerra.*

E é como declaração de guerra que se pode pensar aí uma convicção para a utopia que se desenha também nesta esfera que é $O$ bairro: um projeto para o futuro contra o estatuto de conserva do presente e sua lógica temporal nos interregnos da vida corriqueira, um projeto a-funcional que procura reconstruir um campo de luta. Não só no fato de que temos ali moradores que estão e outros que ainda vêm e talvez alguns que se mudem ou nem venham a habitá-lo, como também na estrutura de pensamento que se constrói ali como "uma comunidade anacrônica e atópica”* e, principalmente, ao seguir o fragmento que desemboca numa proposição em torno do ensaio, como um modo de fazer política. Note-se que pensamos a utopia como "uma experiência radical dos futuros opacos e sombrios", * seguindo uma sugestão que vem de Ernst Bloch, porque se entende aí, segundo ele, que não há escolhas diante de um estado de urgência instalado pelas operações da história, mas que esse estado convive conosco desde que existimos e simplesmente pelo fato de existirmos. Assim, podemos dizer com ele que "a aglomeração das coisas havidas obstrui totalmente as categorias de futuro".* Diz Bloch sobre o que nomeia como "princípio esperança” ou "princípio utópico" que este princípio não se manifesta nem no mundo arcaico-mítico - apesar do êxodo para fora dele-
* (NIETZSCHE, Wilhelm Friedrich. Crepúsculo dos ídolos, ou, Como se filosofia com o martelo. Trad., notas e posfácio Paulo César de Souza. São Paulo: Companhia das Letras, 2006: 7.)

* (Ibidem: 8.)

* (DIDI-HUBERMAN, Georges. Sobrevivência dos vaga-lumes. Trad. Vera Casa Nova e Márcia Arbex. Belo Horizonte: Editora UFMG, 2011: 51.)

* (SOUSA, Edson Luiz André de. Uma Invenção da utopia. São Paulo: Lumme Editor, 2007: 13.)

* (BLOCH, Ernst. O Princípio Esperança. Volume 1. Trad. Nélio Schneider. Rio de Janeiro: UERJ e Contraponto, 2005: 18.) 
* (NIETZSCHE, Wilhelm Friedrich. A gaia ciência. Tradução, notas e posfácio Paulo César de Souza. São Paulo: Companhia das Letras, 2001: 188.) nem no mundo urbano-racionalista - apesar da dialética explosiva. Argumenta que a razão disso é que tanto uma mentalidade quanto a outra são idealistas e pressupõem um mundo feito, acabado e sempre apreciado de modo passivo, incluindo-se aí até um supramundo projetado para além, o do já veio a ser.

Por isso que, para Bloch, pensar um futuro autêntico, que se abre como em processo, pode ser sempre inacessível e estranho a uma contemplação simplista. Pensar uma mudança de mundo, ou seja, pensar o mundo a partir de um desejo de mudança do mundo é pensar também um futuro sem constrangimento - "futuro como o espaço de surgimento inconcluso diante de nós"* - e um passado que não é feito de encantamento. Arma-se aí uma relação com o saber, como disse Nietzsche, e para Bloch, um saber como teoria-práxis consciente, para nos indicar o que está em devir e passível de decisões. Isto se dá, segundo Edson Sousa ao ler Bloch, na clave da utopia como uma "invenção", num afastamento daquilo que tomamos como excesso de familiar para tocar o outro, a alteridade e o exílio; desviar o olhar como forma de redesenhar o espaço contaminado pelo convicto e presente si mesmo quando o outro se recusa a ser igual. Como o que diz Nietzsche: "Que a minha única negação seja desviar o olhar! E, tudo somado e em suma: quero ser, algum dia, apenas alguém que diz Sim!”*

Júlia Vasconcelos Studart é doutora em Teoria Literária, UFSC/Universidade Nova de Lisboa (bolsista CNPq - Capes/2011) e pesquisadora do Núcleo de Estudos Literários \& Culturais. - Nelic. Publicou os livros de ensaios Wittgenstein \& Will Eisner - se numa cidade suas formas de vida $\mathrm{e}$ Livro Segredo e Infâmia; organizou o livro Conversas, diferença n.1-ensaios de literatura etc. E-mail: <juliastudart@gmail.com> 